\title{
USE OF THE LABORATORY TESTS OF SOIL MODULUS IN MODELLING PILE BEHAVIOUR
}

\author{
IRENEUSZ DYKA \\ University of Warmia and Mazury in Olsztyn, Chair of Geotechnics and Road Engineering, \\ ul. Prawocheńskiego 19, 10-720 Olsztyn, Poland, e-mail: i.dyka@uwm.edu.pl
}

\begin{abstract}
This article deals with the question of theoretical description of behaviour of a single pile rested in a layered soil medium. Particular attention is paid to soil modulus which is used in calculation method for pile load-settlement curve. A brief analysis of the results obtained by laboratory tests to assess soil modulus and its nonlinear variability has been presented. The results of tests have been used in triaxial apparatus and resonant column/torsional shear device. There have also been presented the results of load-settlement calculation for a single pile under axial load with implementation of different models of soil modulus degradation. On this basis, possibilities of using particular kinds of laboratory tests in calculation procedure of foundation settlement have been presented as well as further developments of them.
\end{abstract}

\section{INTRODUCTION}

Geotechnical design consists in presentation of such a solution to the geotechnical problem that fulfils requirements of safety conditions for buildings and civil engineering works under maximum loads and other actions. A structure must also perform the assumed functions without excessive displacements. Despite the lack of categorical statement of the necessity of calculating soil deformation in geotechnical standard Eurocode 7, displacement of foundation under the influence of imposed loads is very important for correct design of structure.

In the large majority of cases, engineer design practice is confined to use of surprisingly crude and little complicated soil models. Most often this leads to overestimation of calculated deformations and causes that some unrealistic values of internal forces in structure are obtained. By this reason design of structure requires a new and more complex analytical method and more sophisticated soil models that will enable rational estimation of soil base deformation [11]. This is absolutely necessary for analysis of interaction between different foundation elements like spread foundations, pile foundations, retaining walls for deep excavations, elements of quays, etc., and soil medium.

In such analysis, one cannot use the linear-elastic model of soil behaviour which is characterised by only one constant value of deformation modulus as material parameter [6]. This has been emphasized also in many Polish publications [8], [16].

The observed load-displacement response from static pile load tests also shows nonlinear shape of the curve obtained, see Fig. 1. This follows not only from nonlinearity of soil medium but is also connected with interaction phenomena between pile 
and soil in a narrow zone surrounding shaft and base of pile. In the case of piles a load imposed on the pile top causes non-uniform mobilisation of shaft and base resistances until they reach limiting values at particular points of the pile. This article concerns the usability of laboratory tests for soil modulus assessment.

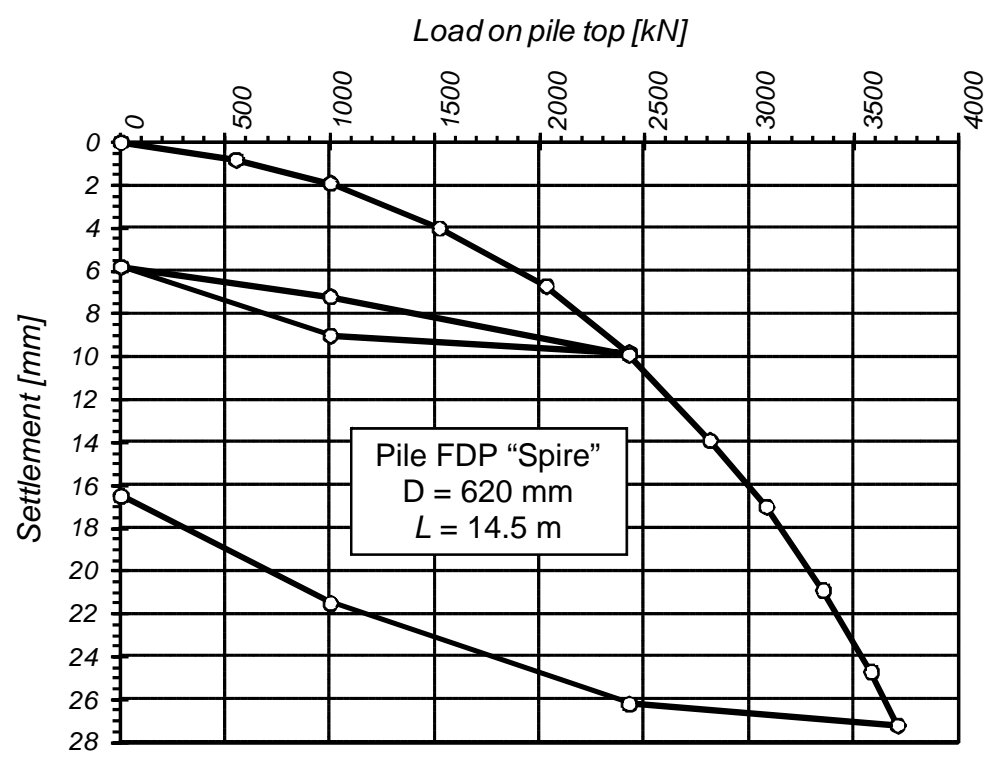

Fig. 1. An example of load-settlement curve resulting from static pile load test

\section{SOIL MODULUS USED IN PILE SETTLEMENT CALCULATION}

Stiffness of soil layers in geotechnical profile is the most important property which has an effect on the shape of mechanical characteristics and resulting values of soil deformations and settlements of foundations. This problem concerning settlement of shallow foundations was presented by Jastrzębska and Łupieżowiec [10].

Stiffness is the property of an elastic medium that determines interdependence between the stress and the strain. For soil stiffness we are not able to assess constant value of it. Soil modulus value decreases when the stress and/or strain increases.

Kirchhoff's modulus $G$ (shear modulus) is most often used in soil modelling because it is independent of the value of Poisson's ratio $v$. Depending on the range of the stress and strain increments we specify three main kinds of modulus used in geotechnics: initial $\left(G_{\max }\right)$, secant $\left(G_{s}\right)$ and tangent $\left(G_{t}\right)$, see Fig. 2. It concerns also Young's elastic modulus $E$. Additionally, other factors affecting the modulus value are the state of stress and its history. 


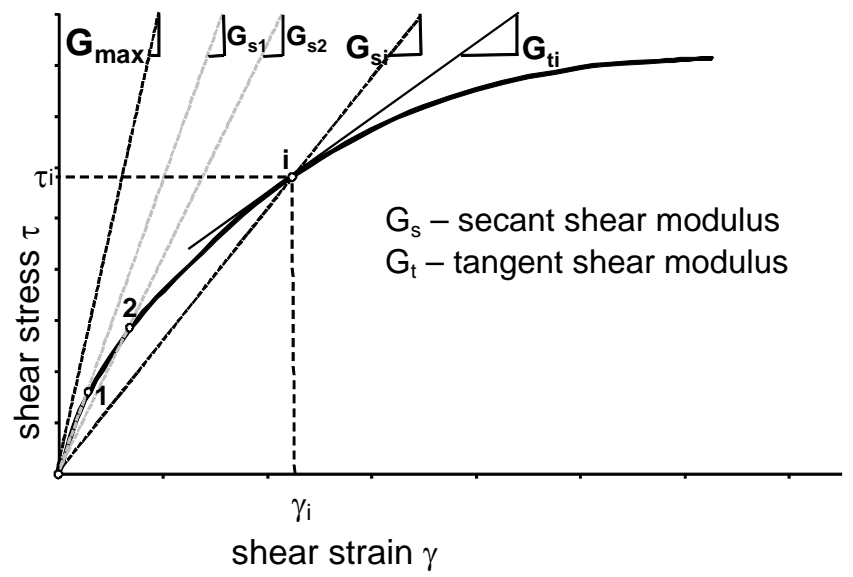

Fig. 2. Change of the soil shear modulus with the strain (after Atkinson [1])

In the case of pile behaviour analysis the modulus value also depends on the method of pile execution (bored, displacement, etc.) and for pile groups we often assume small strain of soil between interacting piles [5]. Additionally, loaded pile considered as elastic rod [9] being in contact with layered soil medium is displaced nonuniformly, depending on the points of pile considered. In effect, different values of stress are mobilized on contact surfaces between pile and soil. So, different places of the soil profile are submitted to different values of strain and consequently they have different values of soil modulus. Additionally, the slide in contact surface occurs when stress value exceeds the limit value of the shaft (or base) resistance. Precise determination of shaft and base resistances in individual soil layer is another question.

It results from the above that assessment of pile behaviour under axial load requires taking into complex consideration many factors affecting nonlinear scheme of load-settlement relationship. One also has to pay attention to proper definition of soil modulus used in the calculation procedure because it can be secant or tangent modulus (Fig. 2). Finally, the model of modulus degradation as a function of strain or actual stress is also very important in numerical procedure of computing.

From the many years' experience it can be stated that subsoil deformations in conditions of normal operational loads are in range of strain $0.001-0.5 \%$. In this range there was lack of methods for laboratory and in-situ testing relevant for determination of nonlinear characteristics of soil behaviour. During the recent past large progress has been made in developing research and analytical techniques aimed to better design of construction. These advances should be used more widely for analysing static soilstructure interaction problems like pile foundation behaviour.

Further development of calculation method for pile and pile group settlement [3] is possible thanks to broad availability of advanced research techniques. Very helpful are especially those techniques which enable determination of initial strain modulus $\left(G_{\max }\right.$ 
or $\left.E_{\max }\right)$ and the model of its nonlinear degradation. The research equipment mentioned is already in possession of the Chair of Geotechnics and Road Engineering, the University of Warmia and Mazury in Olsztyn. The composition of equipment includes: RC/TS device (resonant column/torsional shear), automatic triaxial compression apparatus TRITECH 50 with bender elements and gauges enabling local measurement of strain on specimens with diameter up to $70 \mathrm{~mm}$. The new equipment also includes a static penetrometer CPT with seismic adapter which enables in-situ measurement of shear wave velocity in a soil profile. Recent works concern laboratory and in-situ tests making it possible to assess both the value of soil modulus for small strain and scheme of its degradation with increasing strain.

\section{LABORATORY TEST METHODS FOR SHEAR SOIL MODULUS}

At a very low stress level (strain level), the shear modulus is called initial shear modulus $G_{\max }$. The value of $G_{\max }$ is constant in a narrow range of very small shear strains: $0-10^{-5}$ and as such, is a state parameter [12]. The initial shear modulus has recently become a very important parameter in soil mechanics. Unfortunately, the characteristic shear strains of soils in most types of geotechnical problems are generally in the range of $10^{-1}$ to $10^{-2} \%$. Thus, the modulus values used for settlement calculations and deformation analysis should correspond to that range, for which soil modulus is strongly dependent on the value of strain. When we want to determine a load-settlement curve for a single pile under axial load we need soil modulus corresponding to the small- to intermediate-strain regime, requiring also reduction schemes to be applied for strain above $10^{-3} \%$. Various testing devices and measuring systems can be used for accurate and convenient measurements in different ranges of strain [8]. These include: bender elements, resonant column, torsional shear apparatus, triaxial cells with internal local measurement and with conventional external measurement of displacements. The conventional cyclic triaxial test is used for high shear strain levels $\left(\gamma>10^{-3}\right)$, whereas bender elements and the RC/TS apparatus are used for low strain levels $\left(\gamma<10^{-3}\right)$. Bender element tests are economical and fast and nowadays very popular; however, the results can be affected by many variables and they require careful interpretation [14]. Additionally, bender elements can only be used to measure the shear modulus at very low strain levels $\left(G_{\max }\right)$. Resonant column device $(\mathrm{RC})$, which is the ASTM standard for dynamic characterisation of soils (ASTM D4015-92 2000), provides more consistent test results; and it is considered as the most accurate and reliable, however, the effect of different equipment in making the measurements on the results has not yet been evaluated.

Detailed description of RC/TS apparatus with theoretical background has been presented in the paper of Dyka and Srokosz [4]. In Fig. 3, some results of soil tests in triaxial compression apparatus with on-specimen gauges and $\mathrm{RC} / \mathrm{TS}$ apparatus are 
shown. The results confirm strong nonlinear behaviour of soil in shear strain range $10^{-3}-1 \%$. They also confirm usability of particular types of laboratory tests in particular ranges of strain. A broad range of strain in RC/TS apparatus testifies that it is a very helpful device for determination of the scheme of soil modulus degradation.

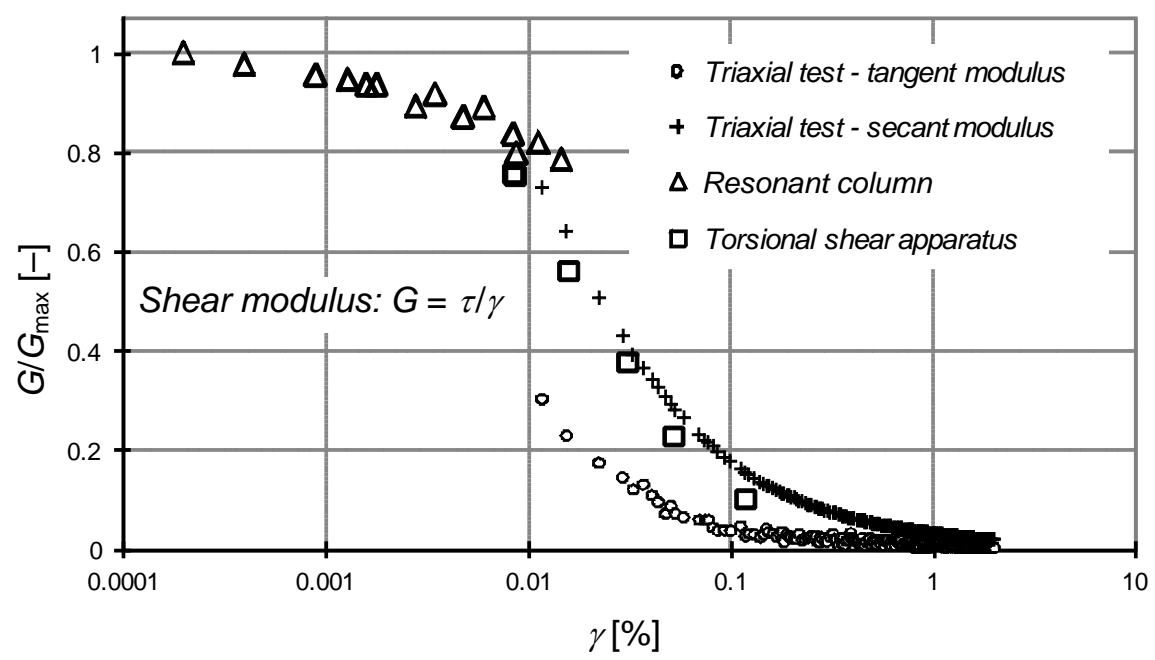

Fig. 3. Results of different tests for soil shear modulus assessment

\section{SCHEME OF SOIL MODULS DEGRADATION AND ITS INFLUENCE ON RESULTS OF LOAD-SETTLEMENT ANALYSIS OF PILE}

The stress-strain behaviour of soils is highly nonlinear with a linear elastic behaviour observed only at very small strains $\gamma<10^{-6}$. As a consequence, for a reliable calculation concerning geotechnical problems of settlement we need to know the function of soil modulus degradation with stress-strain increase. The quantification of modulus degradation with the level of shear strain is currently one of the most active research areas in geotechnical engineering. A number of different expressions have been proposed to represent modulus degradation, just to mention: Kondner (1963), RambergOsgood, Duncan and Chang (1970), Seed and Idriss (1971), Hardin and Drnevich (1972), Jardine et al. (1986), Prevost and Keane (1990), Vucetic and Dobry (1991), Tatsuoka and Shibuya (1992), Fahey and Carter (1993), Whittle and Kavvadas (1994), Puzrin and Burland (1996, 1998), Tatsuoka et al. (2001), Darrendelli (2001).

The earliest models of soil modulus degradation were based on a hyperbolic shape. The simple hyperbola offers the convenience in that only two parameters are required: initial shear modulus $-G_{\max }$, and maximum shear stress $-\tau_{\max }$. For example, a model of Duncan and Chang (1970) is described by the equation 


$$
G=G_{\max }\left(1-\frac{\tau}{\tau_{\max }}\right) .
$$

However, the simple hyperbola fails to adequately model the complete and complex behaviour of soils in most instances over the full range of strains. The monotonic static loading shows a more severe decay with strain (Mayne et al. 1999).

In the method developed for pile settlement calculation [3], [9], there has also been used the model of soil modulus degradation for each step of load increment. Originally, there has been used the shape of modified hyperbola based on Chow [2]:

$$
\begin{gathered}
G=G_{\max } \cdot\left(1-R_{f} \frac{\tau}{\tau_{\max }}\right)-\text { for secant modulus, } \\
G=G_{\max } \cdot\left(1-R_{f} \frac{\tau}{\tau_{\max }}\right)^{2}-\text { for tangent modulus, }
\end{gathered}
$$

where $R_{f}=0.5 \div 0.9$.

The shape of this model for tangent modulus and $R_{f}=0.9$ is marked as model A in Fig. 4.

Fahey and Carter [7] have proposed a model of soil modulus degradation in the following form

$$
G=G_{\max } \cdot\left(1-f\left(\frac{\tau}{\tau_{\max }}\right)^{g}\right)
$$

where $f$ and $g$ are fitting parameters. For a conventional hyperbola, $f=g=1$. As was stated by Mayne [13], for monotonic loading of uncemented and unaged quartzitic sands and insensitive and unstructured clays, values of $f=1$ and $g=0.3$ appear to give reasonable approximations for first-order evaluations (model B in Fig. 4).

Van Impe and De Clercq [15] have used the scheme of soil modulus degradation in the procedure of pile settlement calculation (Fig. 5), which can be written as follows

$$
G= \begin{cases}G_{\max } & \text { when } \gamma \leq 10^{-5}, \\ -G_{\max }(0.3 \cdot \log \gamma+0.5) & \text { when } \gamma \in\left(10^{-5}, 10^{-2}\right), \\ 0.1 \cdot G_{\max } & \text { when } \gamma \geq 10^{-2} .\end{cases}
$$

The results of laboratory tests (Fig. 3) suggest that the rate of modulus value degradation would be higher in the range of strain $0.01 \div 0.1 \%$. Consequently, it would be proposed to change soil modulus value according to model C in Fig. 4. 


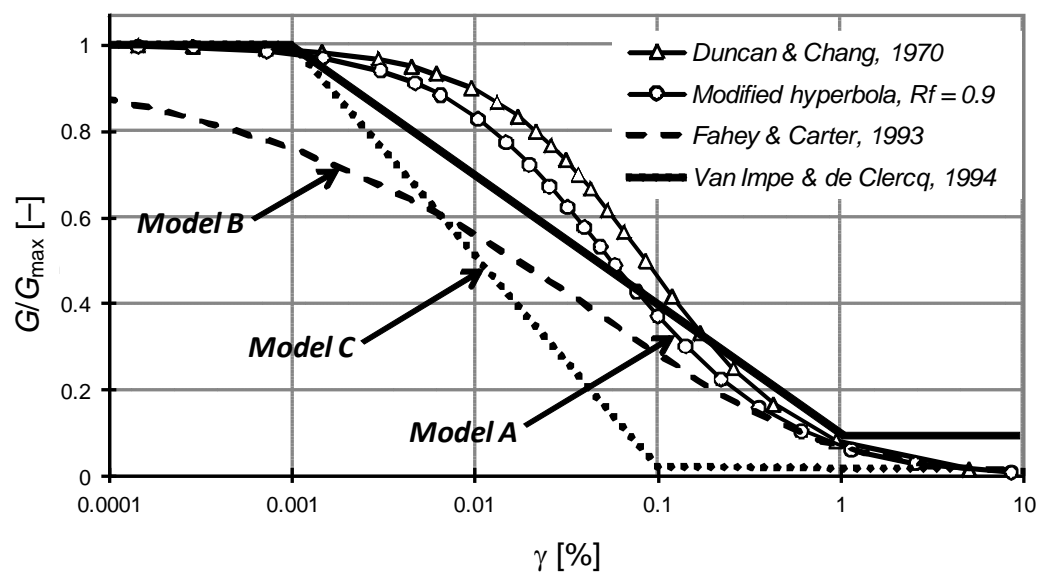

Fig. 4. Comparison of some models of soil modulus degradation

Differences between the models presented show that implementation of a particular model in calculation procedure has to be preceded by an analysis of the influence of the model introduced on calculation results. The influence of selected model on the obtained load-settlement curve of a single pile is presented in Fig. 5. It seems that the greatest impact on the results obtained has proper assessment of modulus degradation function for strain of range $0.01 \div 1 \%$.

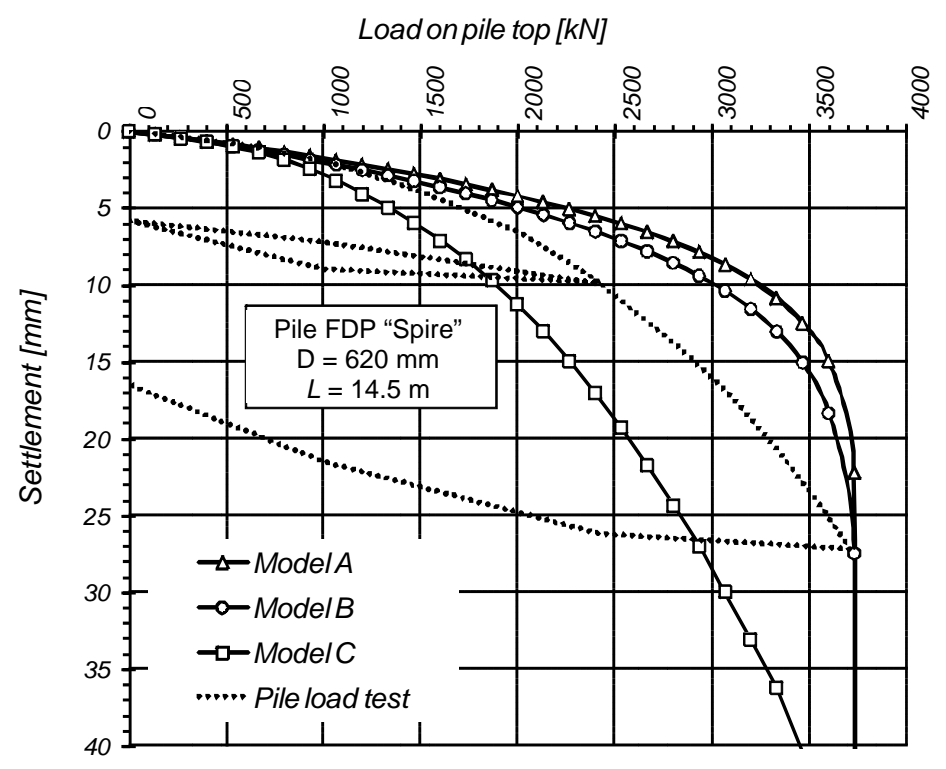

Fig. 5. Influence of soil modulus degradation model on calculation results of pile load-settlement curve 


\section{CONCLUSION}

The best way of assessing pile behaviour under axial load is to determine loadsettlement curve. The shape of this relation depends on many factors and parameters of soil layers (limit resistance of pile shaft and base, modulus of deformation, etc.). One of the most difficult soil parameters to assess is soil stiffness. Stiffness parameters, variously defined, are nonlinear functions of stress (strain) level. Different laboratory tests are performed in different ranges of strains.

Proper value of initial soil modulus and adequate choice of soil modulus degradation model with relevant fitting parameters, in consequence, allow us to obtain reliable assessment of behaviour of foundation under work loads. For that purpose we need many results of laboratory tests on soil samples to confirm relation between soil modulus value and level of strain, results of in-situ pile load tests and relevant calculation method of pile load-settlement behaviour. There are not many results of such analysis for Polish geotechnical conditions. Recently conducted works are feasible thanks to the new research equipment including automatic triaxial compression apparatus with local measurement of strain, bender elements for the measurement of initial shear modulus and first of all the resonant column/torsional shear device that enables estimation of change of soil modulus as a function of shear strain in the range $\gamma=$ $10^{-4} \div 10^{-1} \%$.

The proper value of soil modulus for very small strain and implementation of the relevant model of soil modulus degradation in numerical procedure of calculation enables a reliable assessment of foundation settlement and values of internal forces in the whole structure.

\section{REFERENCES}

[1] AtKinson J.H., Non-linear soil stiffness in routine design, Geotechnique, 2000, 50, No. 5, 487-508.

[2] CHOw Y.K., Analysis of Vertically Loaded Pile Groups, International Journal for Numerical and Analytical Methods in Geomechanics, 1986, Vol. 10, 59-72.

[3] DYKA I., Analysis and calculation method of pile group settlement (in polish), PhD Thesis, Technical University of Gdańsk, Gdańsk, 2001.

[4] Dyka I., Srokosz P.E., Badania gruntu w aparacie RC/TS, Część 1, Inżynieria Morska i Geotechnika, will be printed in 2012.

[5] Dyka I., W sprawie obliczania osiadania pali w grupie, Inżynieria i Budownictwo, No. 12/2009, 669-673.

[6] FAHEY M., Deformation and in situ stress measurement, Proceedings of International Conference on Site Characterization, ICS'1, Atlanta, GA, April 1998, Vol. 1, 49-68.

[7] FAHEY M., CARTER J.P., A finite element study of the pressuremeter in sand using a nonlinear elastic plastic model, Canadian Geotechnical Journal, 1993, 30, 2, 348-362.

[8] GRYCZMAŃSKi M., State of the art in modelling of soil behaviour at small strains, Architecture Civil Engineering Environment, No. 1/2009, The Silesian University of Technology. 
[9] GwizdaŁa K., Dyka I., Analityczna metoda prognozowania krzywej osiadania pala pojedynczego, Inżynieria i Budownictwo, 2001, No. 12, 729-733.

[10] JASTRZĘBSKA M., ŁUPIEŻOWIEC M., The influence of the choice of strain modulus value on foundation settlement, Studia Geotechnica et Mechanica, 2011, Vol. XXXIII, No. 2, 31-39.

[11] Massarsch K.R., Deformation properties of fine-grained soils from seismic tests, Keynote lecture of International Conference on Site Characterization, ICS'2, Porto, September 2004, 19-22.

[12] Mayne P.W. et al., Geomaterial Behavior and Testing, Proceedings of 17-th International Conference on Soil Mechanics and Geotechnical Engineering, Alexandria, Egypt, 5-9 October 2009, $2777-2872$.

[13] Mayne P.W., Schneider J.A., Martin G.K., Small- and large-strain soil properties from seismic flat plate dilatometer tests, Pre-Failure Deformation Characteristics of Geomaterials, Vol. 1, (Torino), Balkema, Rotterdam, 1999, 419-426.

[14] SRokosz P.E., Badania gruntu elementami bender, Inżynieria Morska i Geotechnika, 2012, 1, 29-38.

[15] Van Impe W.F., de ClercQ Y., A Piled Raft Interaction Model, Proc. of 5-th International Conference and Exhibition on Piling and Deep Foundations - DFI '94, Bruges, Belgium, 13-15 June 1994.

[16] WdowsKa M.K., WudzKA A., Zmiana sztywności gruntów spoistych ze względu na zakres rozpatrywanych odkształceń, Proceedings of 14 KKMGiG, Białystok-Augustów 2006, Zeszyty Naukowe Politechniki Białostockiej, Budownictwo, Zeszyt 29, 243-254.

[17] ASTM D4015-92 2000, Standard Test Methods for Modulus and Damping of Soils by the ResonantColumn Method. 